\title{
Ion Channel Trafficking: Control of Ion Channel Density as a Target for Arrhythmias?
}

\author{
Elise Balse ${ }^{1 *}$ and Hannah E. Boycott ${ }^{2}$ \\ 1 Unité de Recherche sur les Maladies Cardiovasculaires, le Métabolisme et la Nutrition, Faculté de Médecine \\ Pitié-Salpêtrière, Sorbonne Universités, UPMC Univ. Paris VI, Inserm, UMRS 1166, Université Pierre et Marie Curie, Paris, \\ France, ${ }^{2}$ Department of Cardiovascular Medicine, John Radcliffe Hospital, University of Oxford, Oxford, United Kingdom
}

OPEN ACCESS

Edited by:

Marcel van der Heyden, University Medical Center Utrecht,

Netherlands

Reviewed by:

Anna Weinzinger

University of Vienna, Austria

Flavien Charpentier,

Institut National de la Santé et de la

Recherche Médicale, France

*Correspondence:

Elise Balse

elise.balse@upmc.fr

Specialty section:

This article was submitted to

Cardiac Electrophysiology,

a section of the journal

Frontiers in Physiology

Received: 23 August 2017 Accepted: 02 October 2017 Published: 17 October 2017

Citation:

Balse E and Boycott HE (2017) Ion Channel Trafficking: Control of Ion Channel Density as a Target for Arrhythmias? Front. Physiol. 8:808. doi: 10.3389/fphys.2017.00808
The shape of the cardiac action potential (AP) is determined by the contributions of numerous ion channels. Any dysfunction in the proper function or expression of these ion channels can result in a change in effective refractory period (ERP) and lead to arrhythmia. The processes underlying the correct targeting of ion channels to the plasma membrane are complex, and have not been fully characterized in cardiac myocytes. Emerging evidence highlights ion channel trafficking as a potential causative factor in certain acquired and inherited arrhythmias, and therapies which target trafficking as opposed to pore block are starting to receive attention. In this review we present the current evidence for the mechanisms which underlie precise control of cardiac ion channel trafficking and targeting.

Keywords: potassium channels, sodium channel, arrhythmias, cardiac, trafficking, accessory proteins

\section{FUNCTIONAL EXPRESSION OF ION CHANNELS IN THE SARCOLEMMA AND CARDIAC EXCITABILITY}

The function of the heart is governed by the electrical and mechanical activity of myocytes. The functional expression of several different types of ion channels in the myocyte sarcolemma determines the shape and duration of the action potential (AP), and therefore controls the effective refractory period (ERP) of the myocardium. The ERP is a protective mechanism that keeps the heart rate in check and thus prevents arrhythmias. Any prolongation or shortening of the ERP is therefore potentially arrhythmogenic. Most genetic arrhythmias are caused by mutations which alter the biophysical properties of ion channels. However, the proper functional expression of ion channels can be disrupted at several points including at the transcriptional, translational, and post-translational levels. In the last two decades, studies have emerged in which mutations carried by ion channels have been shown to be linked to trafficking defects, resulting in retention and/or degradation of the channel early in the trafficking process.

The density of active ion channels in specific membrane domains is a dynamic process resulting from the concomitant and antagonistic action of anterograde (exocytosis, recycling) and retrograde (internalization) pathways. Targeting and stabilization of these channels by anchoring partners in specialized domains of the sarcolemma also dynamically regulate the electrical activity of the cell (Balse et al., 2012; Figure 1).

The majority of mutations related to trafficking defects involve endoplasmic reticulum (ER) exit defects, leading to targeting of misfolded channels to degradation by the ERAD system (endoplasmic reticulum-associated degradation, lysosomal, or proteasomal). Such mutations have been identified for HERG (Furutani et al., 1999), KCNQ1 (Gouas et al., 2004), and SCN5A (Valdivia et al., 2004) and associated with long QT and Brugada syndromes. Sorting signals carried by 
ion channels also are necessary for ER and trans-Golgi network exit (TGN) (Kupershmidt et al., 2002). A mutation involving an endocytotic defect of TRPM4 has also been identified in human progressive familial heart block type I (Kruse et al., 2009). Finally, another crucial factor is the association (early or late) of ion channels with ancillary subunits, chaperones, and anchoring partners that are involved in channel function and localization.

\section{BEYOND CHANNELOPATHIES: TRAFFICKING PROCESSES AS REGULATORS OF CARDIAC ACTION POTENTIAL}

Trafficking and targeting of integral membrane proteins, including ion channels and receptors, have been explored in other cell types such as epithelial cells and neurons. Although these studies have yielded great insights, these mechanisms have not been studied extensively in cardiomyocytes. Such research may provide insight into the regulation of cardiac excitability via ion channel trafficking. Although trafficking defects have been reported for certain ion channel mutations, and are associated with retention in intracellular organelles, the characterization of intracellular trafficking in control and disease conditions are largely lacking in native cardiomyocytes. The fact that these cells are highly structurally and functionally specialized suggests that trafficking and targeting of cardiac ion channels may involve unique and specific pathways. Furthermore, the propagation of electrical activation within the myocardium is a complex process controlled by the spatial/differential distribution of ion channels within single cardiomyocytes that eventually establishes the anisotropic ratio. The underlying mechanisms regulating ion channel targeting to sarcolemmal subdomains, and tethering into macromolecular complexes remains a largely unanswered, yet important question.

In acquired arrhythmias such as heart failure and atrial fibrillation, ion channel dysfunction and electrical remodeling are often associated with tissue remodeling including hypertrophy/dilatation, replacement and interstitial fibrosis, and gap junction disorganization (Rucker-Martin et al., 2006). In this context, abnormal trafficking and targeting of cardiac ion channels emerge as important pathogenic factors of the electrical remodeling (Schotten et al., 2011). Importantly, increased knowledge of the pathways underlying cardiac ion channel trafficking may yield novel drug targets which lack the problems associated with conventional pore block therapies. Such therapies are frequently highly non-selective and have numerous unwanted side effects. The purpose of this mini-review is to provide an overview of the mechanisms of trafficking of ion channels in native cardiomyocytes that could potentially result in the discovery of new targets for antiarrhythmic therapies.

\section{HYPOKALEMIA AND HERG CHANNEL REGULATION}

The $\mathrm{I}_{\mathrm{Kr}}$ current is encoded by the human ether-a-go-go-related gene (HERG, also known as KCNH2) in the heart (Sanguinetti et al., 1995; Trudeau et al., 1995). HERG mutations resulting in reduced $\mathrm{I}_{\mathrm{Kr}}$ cause type 2 long QT syndrome (LQT2), which predisposes individuals to life-threatening arrhythmias. HERG mutations often disrupt the forward trafficking of hERG (thereby reducing sarcolemmal expression of the channel), and subsequently result in decreased $I_{\mathrm{Kr}}$ (Anderson et al., 2006). The hERG channel is also a notorious target for several classes of drugs that engender acquired long QT syndrome (LQTS) (Sanguinetti and Tristani-Firouzi, 2006). For instance, LQTS and Torsades de pointes are exacerbated by hypokalemia, with a moderate increase in serum $\left[\mathrm{K}^{+}\right]$capable of correcting LQTS in some patients (Compton et al., 1996). Hypokalemia is therefore considered a risk factor for LQTS and sudden cardiac death.

Guo and colleagues elegantly revealed how the plasma membrane density of hERG channels is regulated under physiological and pathophysiological (hypokalemia) conditions. They showed that lowering extracellular potassium drastically accelerated hERG internalization and degradation both in overexpression systems and native $I_{\mathrm{Kr}}$ in a hypokalemia rabbit model (Guo et al., 2009). Rabbits fed with low-K ${ }^{+}$diet showed prolonged QTc correlated to significantly prolonged $\mathrm{APD}_{90}$. In vitro, exposure to $0 \mathrm{mM} \mathrm{K}^{+}$medium completely and reversibly eliminated $I_{\mathrm{Kr}}$ without significant effects on other potassium currents. The decrease in $I_{\mathrm{Kr}}$ accompanied reduced expression of hERG, combined with reduced surface expression of the channel. Finally, they showed that $0 \mathrm{mM} \mathrm{K}^{+}$medium induced the internalization of hERG by increasing ubiquitylation and resulted in lysosomal degradation (Guo et al., 2009). These findings provide a potential mechanism for hypokalemiainduced exacerbation of LQTS.

\section{LIPIDIC CONTENT AND $\mathrm{K}_{\mathrm{V}} 1.5$ CHANNEL REGULATION}

Cardiac excitability can be regulated by cellular lipid content. Free cholesterol is a major lipid class shown to regulate membrane fluidity, curvature, and stiffness (Lundbaek et al., 1996). The function of several cardiac ion channels are regulated directly by cholesterol, which modulates channel properties (Oliver et al., 2004; Epshtein et al., 2009).

The $I_{\text {Kur }}$ current, carried by $\mathrm{K}_{\mathrm{V}} 1.5$ channels, is an important component of atrial repolarization (Fedida et al., 1993; Wang et al., 1993) and has been implicated in the pathology of atrial fibrillation (Van Wagoner et al., 1997; Brundel et al., 2001). The groups of D. Fedida and J. Martens contributed substantially to the study of the trafficking of $\mathrm{K}_{\mathrm{V}} 1.5$ channel in expression systems (McEwen et al., 2007; Steele et al., 2007). Trafficking of vesicles is regulated by several Rab GTP-ases, involved at every stage of the process; regulating sorting, tethering and docking of trafficking vesicles. The early endosome (EE), associated with Rab4, mediates fast recycling while the recycling endosome, associated with Rab11, coordinates the slow recycling of proteins back to the cell membrane.

We showed that membrane cholesterol depletion via methyl$\beta$-cyclodextrin $(\mathrm{M} \beta \mathrm{CD})$ increased the number of functional $\mathrm{K}_{\mathrm{V}} 1.5$ channels in the sarcolemma of atrial myocytes, also reducing their mobility as shown by Fluorescence recovery After Photobleaching (Balse et al., 2009). Cholesterol depletion triggers 
exocytosis of ion channels from sub-membrane compartments. Indeed, the overexpression of a dominant negative (DN) form of Rab11 (associated with the recycling endosome), prevented the current increase upon $\mathrm{M} \beta \mathrm{CD}$ treatment whereas overexpression of a DN form of Rab4, associated with the early endosome, did not. The recycling endosome, considered a slow route for ion channel recycling (Steele et al., 2007), is particularly sensitive to cholesterol depletion as rapid dissociation $(<10 \mathrm{~min})$ of the channel from the vesicle was observed (Balse et al., 2009). These results showed that channel turnover can be modified by changes in the lipid environment and that sub-membrane storage compartments can be recruited to modify the electrical properties of cardiomyocytes.

\section{MECHANICAL CHALLENGE AND $K_{\mathrm{V}} 1.5$ CHANNEL REGULATION}

Cardiomyocytes are exposed to mechanical forces when the heart contracts. These forces consist of stretch, shear and strain constraints. Shear forces in the myocardium are primarily generated by the movement of sheets of cardiomyocytes sliding relative to each other when the muscle contracts, as well as by blood flow during the cardiac cycle (LeGrice et al., 1995; Costa et al., 1999). Increased shear stress stimulates intracellular calcium transients (Morad et al., 2005), increases the beating rate of neonatal ventricular myocytes (Lorenzen-Schmidt et al., 2006), and triggers propagating APs in monolayers of ventricular myocytes (Kong et al., 2005).

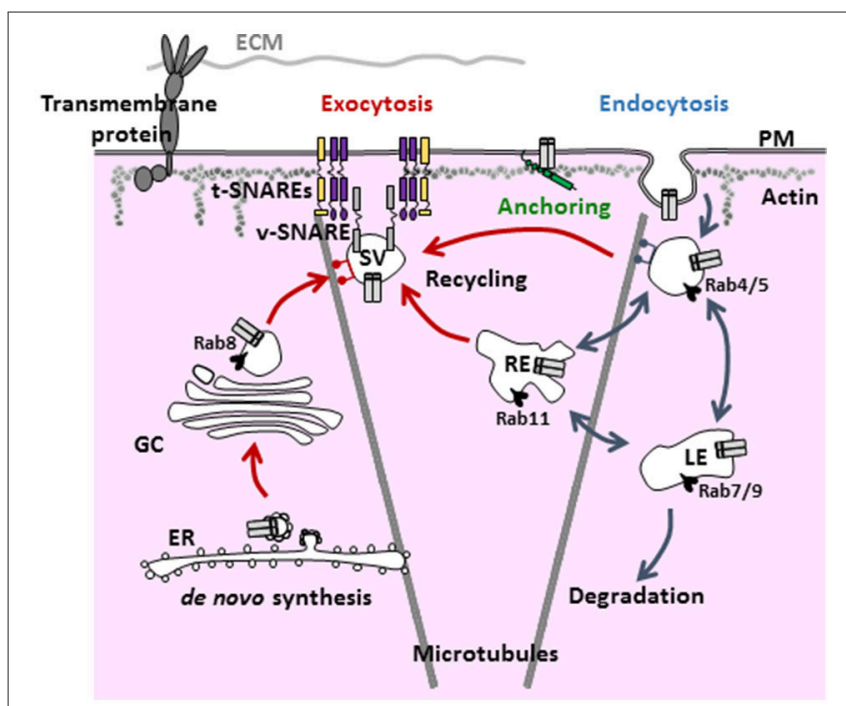

FIGURE 1 | General scheme of the various steps and regulators involved in the trafficking of ion channels. Ion channels are targeted to the plasma membrane via the anterograde and recycling pathways (red arrows). Once targeted to a specialized domain of the membrane, ion channels are stabilized by anchoring partners/associate subunits to be functional (green). Then, signals for internalization (blue arrows) lead to either degradation or recycling. PM, plasma membrane; EE, early endosome; LE, late endosome; ECM, extracellular matrix; RE, recycling endosome; GC, Golgi complex; ER, endoplasmic reticulum; SV, secretory vesicle.
We showed that in rat atrial myocytes shear stress activates a large outward current, mirrored by a decrease in AP duration (Boycott et al., 2013). The main ion channel mediating the increase in current $\mathrm{K}_{\mathrm{V}} 1.5$, which was recruited from subcellular compartments to the sarcolemma, a phenomenon which was directly observed by TIRF microscopy. The donor compartment was again identified as the recycling endosome. $\mathrm{K}_{\mathrm{V}} 1.5$ channel exocytosis requires integrin signaling through focal adhesion kinase (FAK) and relies on an intact microtubule system. We also found that the response was dysregulated in a model of chronic hemodynamic overload. Hypertrophied atrial myocytes had reduced $\mathrm{K}_{\mathrm{v}} 1.5$ expression, despite an increase in basal $I_{K u r}$. The response of these cardiomyocytes to shear stress was reduced, and the kinetics altered. Our results suggested chronically increased mechanical stress over activates the integrin signaling pathway, resulting in an increased $I_{K u r}$, AP shortening and a reduction in the capability of cells to respond to shear stress (Boycott et al., 2013). Thus, pools of $K_{V} 1.5$ from the slow recycling route may comprise an inducible reservoir mediating faster atrial repolarization. The shortening of the AP observed following heart failure in the atria could be partly explained by a shift in the trafficking balance toward increased exocytosis.

\section{MODULATION OF $K_{v} 1.5$ INTERNALIZATION BY ANTIARRHYTHMICS}

Whereas conventional antiarrhythmic drugs generally target ion permeability by binding to the pore of the channel, increasing evidence suggests some compounds can indirectly disrupt protein trafficking. In this context, sustained efforts have been conducted to develop antiarrhythmic agents that affect channel trafficking, notably hERG channels blockers that stabilize misfolded channels and rescue hERG trafficking mutants (Wible et al., 2005).

The group of J. Martens has been at the forefront of investigations into the potential antiarrhythmic properties of drugs which acutely modulate the surface density of functional channels (Schumacher et al., 2009). The class I antiarrhythmic drug quinidine is known to inhibit $I_{\text {Kur }}$ current through open-channel block of $\mathrm{K}_{\mathrm{V}} 1.5$ channel. Using an immunocytochemical approach to quantify surface and internalized channels, Schumacher and colleagues showed that quinidine dose-dependently induced the internalization of $\mathrm{K}_{\mathrm{V}} 1.5$ channel over short-time frames $(10 \mathrm{~min})$ in the HL-1 cell line and in dissociated neonatal mouse myocytes. The effect of quinidine was stereospecific as quinine has no effect on $\mathrm{K}_{\mathrm{V}} 1.5$ channel surface density (despite exerting the pore-block effect of its stereoisomer) and subunit-dependent, as the $\mathrm{K}_{V} 1.5$ related channels $\mathrm{K}_{\mathrm{V}} 2.1$ or $\mathrm{K}_{\mathrm{V}} 4.2$ did not show internalization at the same time points and doses. In addition, quinidineinduced $\mathrm{K}_{\mathrm{V}} 1.5$ channel internalization followed the same endocytotic pathway as constitutive endocytosis (as previously identified Choi et al., 2005), being microtubule-dependent and dynamin-mediated. Finally, whereas acute treatment allows channel recycling to the surface, chronic treatment with a 
clinical-compatible concentration led to channel degradation through the proteasome. This pharmacological control of $\mathrm{K}_{\mathrm{v}} 1.5$ surface expression and trafficking represents a novel mechanism by which drug stimulated endocytosis of an ion channel may be utilized as an anti-arrhythmic tool.

\section{ORGANIZATION OF ION CHANNEL MACROMOLECULAR COMPLEXES}

It is noteworthy that emerging evidence challenges the assumption that ion channels function as homogeneous complexes. Rather, it seems likely that ion channels form macrocomplexes with other ion channels, and that these complexes contribute to the stabilization of channels at the sarcolemma, and facilitate proper electrical conduction. The MAGUK protein SAP97 contributes to the formation of macromolecular complexes involving different ion channel families: $\mathrm{K}_{\mathrm{V}} 1.5$ (Godreau et al., 2002; Abi-Char et al., 2008), $\mathrm{K}_{\mathrm{V}} 4 . \mathrm{x}$ (El-Haou et al., 2009; Gillet et al., 2015), Kir2.x (Leonoudakis et al., 2001; Milstein et al., 2012; Matamoros et al., 2016), and $\mathrm{Na}_{\mathrm{v}} 1.5$ (Petitprez et al., 2011; Milstein et al., 2012), SAP97 also couples ion channels to signaling pathways, allowing the regulation of $\mathrm{K}_{\mathrm{V}} 4$.x channels by CaMKII (El-Haou et al., 2009). An important recent breakthrough showed that SAP97 regulates the formation of $\mathrm{Na}_{\mathrm{V}} 1.5 / \mathrm{Kir} 2.1$ complexes, the two critical channels underlying $I_{\mathrm{K} 1}$ and $I_{\mathrm{Na}}$, respectively. These currents are responsible for maintenance of the resting membrane potential and rapid depolarization during the upstroke of the AP (Milstein et al., 2012). This multi-channel organization enables reciprocal modulation, contributing to maintenance of normal cardiac excitability. Interestingly, co-expression with $\mathrm{Na}_{\mathrm{v}} 1.5$ seems to reduce internalization of Kir2.1, suggesting that participation in a macromolecular complex reduces anterograde trafficking of Kir2.1 (Milstein et al., 2012). Another example of multi-channel organization for $\mathrm{Na}_{V} 1.5 / \mathrm{Kir} 2 \mathrm{x}$, but mediated by syntrophin, has been recently reported (Matamoros et al., 2016). In addition to $\mathrm{Na}_{\mathrm{v}} 1.5$, other cardiac ion channels have been shown to interact. For example, the KCNQ1/KCNE1 genes that encode $I_{\mathrm{Ks}}$ (Barhanin et al., 1996; Sanguinetti et al., 1996) interact with hERG, and the channels can reciprocally regulate (Ehrlich et al., 2004; Ren et al., 2010; Organ-Darling et al., 2013), with KCNQ1 also functioning as a chaperone for hERG trafficking (Biliczki et al., 2009). In the context of hypokalemia, KCNQ1/hERG coexpression slowed the internalization of mature, i.e. cell-surface expressed, hERG channels whereas KCNQ1 alone is not sensitive to hypokalemia (Guo et al., 2011). As the association between hERG and KCNQ1 only occurs at the plasma membrane, KCNQ1 likely contributes to hERG membrane stability.

\section{MODULATION OF ION CHANNEL ANTEROGRADE TRAFFICKING BY PARTNER PROTEINS}

A fascinating question relates to the nature of the molecular mechanisms which regulate ion channel targeting into distinct subdomains of the sarcolemma and their tethering in large molecular complexes. Cardiac myocytes are structurally and functionally highly polarized cells. While the transmission of the AP between myocytes occurs at the intercalated disc (ID), the AP is conducted along the myocyte at the lateral membrane (LM).

The direct targeting of hemichannels to the ID via the microtubule plus-end-tracking protein EB1 (Shaw et al., 2007) and the targeting of Cav1.2 to T-tubules by BIN1, a protein involved in membrane invagination and endocytotic processes (Hong et al., 2012) have been important major discoveries.

Recently, the spatial distribution of $\mathrm{Na}_{V} 1.5$ has received interest. Whereas $\mathrm{Na}_{V} 1.5$ is highly concentrated at the ID (3 to 8 fold larger current), $\mathrm{Na}_{\mathrm{V}} 1.5$ channels at the LM show a lower density (Verkerk et al., 2007; Lin et al., 2011). This differential distribution of $\mathrm{Na}_{\mathrm{V}} 1.5$ channels favors the anisotropic conduction of the myocardial depolarization wave (Spach, 1999). Several partners of $\mathrm{Na}_{\mathrm{v}} 1.5$ have been identified such as gap junctional (i.e., connexin-43), desmosomal (plakophilin-2), actin cytoskeleton-binding (ankyrin-G), and the MAGUK protein SAP97 at the ID and syntrophin at the LM (for review see Shy et al., 2014). All these partners exert a positive regulatory effect on $I_{\mathrm{Na}}$ since their silencing in vitro, Knock Out in vivo or reduced expression in the Duchenne muscular dystrophy mouse model leads to reduced sodium current and localization. However, whether these proteins are involved anterograde trafficking of $\mathrm{Na}_{V} 1.5$ or associate with the channel once inserted in the plasma membrane to stabilize it is not clear. Recently, we have characterized a new partner of the $\mathrm{Na}_{V} 1.5$ channel in the myocardium, the MAGUK protein CASK. CASK is located at the LM, in association with the syntrophin/dystrophin complex. In contrast with other $\mathrm{Na}_{V} 1.5$ partners, CASK negatively regulates $I_{\mathrm{Na}}$ by impeding $\mathrm{Na}_{\mathrm{V}} 1.5$ anterograde trafficking to the LM (Eichel et al., 2016). In dilated human atria, associated with AF or valve regurgitation, expression of CASK is reduced without affecting its localization. The consequence of this would likely be increased $I_{\mathrm{Na}}$ at the LM and could be considered detrimental for cardiac anisotropy. Keeping with the recent discovery that SAP97 is necessary for the interaction between $\mathrm{Na}_{V} 1.5$ and Kir2.1 (Milstein et al., 2012), MAGUK proteins could be major partners for the organization of multi-channel complexes.

\section{CONCLUSION}

Although only proven in vitro at present, early ER/Golgi trafficking rescue has been shown to be feasible for traffickingdefective mutant channels by temperature decrease, Hsp70 and 91 cytosolic chaperones, and pharmacological chaperones. Pharmacological chaperones include channel blockers, such as anti-histamines (Astemizole), anti-serotoninergic (Cisapride) and antiarrhythmics (e.g., E-4031 for hERG), that are difficult to manipulate as they can also block the channel and worsen the disease. However, certain pore-blocking drugs, such as fexofenadine, have been shown to rescue hERG trafficking of some mutant channels at concentrations far below the IC50 for pore-block (Rajamani et al., 2002). Furthermore, in an iPSC model of LQTS2 in which hERG was not expressed at the sarcolemma, sarcolemmal hERG expression was achieved using the proteasomal inhibitor ALLN, which allowed the re-trafficking and functional expression of the channel (Mehta et al., 2014). These studies highlight the relevance of research into 
pharmacological rescue of trafficking deficient mutant channels. Low molecular weight compounds such as DMSD, TMD and glycerol act as nonspecific chemical chaperones mostly likely by stabilizing proteins during folding and maturation (Kaufman and Ficker, 2003). In acquired cardiopathies, three pathways are worthy of special attention: the recycling endosome/Rab11 pathway, the endocytosis/dynamin/microtubule pathway and, the association of ion channels with specific partners for anterograde trafficking and correct targeting to specialized membrane subdomains of the myocyte. Future studies are necessary to explore the specific roles of ion channel partners on ion channel trafficking/targeting vs. membrane scaffolding to understand the relative contribution of these proteins in dictating cardiac excitability and function under normal and pathological conditions. The highly specialized architecture of the cardiomyocyte dictates that more studies in native

\section{REFERENCES}

Abi-Char, J., El-Haou, S., Balse, E., Neyroud, N., Vranckx, R., Coulombe, A., et al. (2008). The anchoring protein SAP97 retains Kv1.5 channels in the plasma membrane of cardiac myocytes. Am. J. Physiol. Heart Circ. Physiol. 294, H1851-H1861. doi: 10.1152/ajpheart.01045.2007

Anderson, C. L., Delisle, B. P., Anson, B. D., Kilby, J. A., Will, M. L., Tester, D. J., et al. (2006). Most LQT2 mutations reduce Kv11.1 (hERG) current by a class 2 (Trafficking-Deficient) mechanism. Circulation 113, 365-373. doi: 10.1161/CIRCULATIONAHA.105.570200

Balse, E., El-Haou, S., Dillanian, G., Dauphin, A., Eldstrom, J., Fedida, D., et al. (2009). Cholesterol modulates the recruitment of Kv1.5 channels from Rab11associated recycling endosome in native atrial myocytes. Proc. Natl. Acad. Sci. U.S.A. 106, 14681-14686. doi: 10.1073/pnas.0902809106

Balse, E., Steele, D. F., Abriel, H., Coulombe, A., Fedida, D., and Hatem, S. N. (2012). Dynamic of ion channel expression at the plasma membrane of cardiomyocytes. Physiol. Rev. 92, 1317-1358. doi: 10.1152/physrev.00041.2011

Barhanin, J., Lesage, F., Guillemare, E., Fink, M., Lazdunski, M., and Romey, G. (1996). K(V)LQT1 and lsK (minK) proteins associate to form the I(Ks) cardiac potassium current. Nature 384, 78-80. doi: 10.1038/384078a0

Biliczki, P., Girmatsion, Z., Brandes, R. P., Harenkamp, S., Pitard, B., Charpentier, F., et al. (2009). Trafficking-deficient long QT syndrome mutation KCNQ1-T587M confers severe clinical phenotype by impairment of KCNH2 membrane localization: evidence for clinically significant IKr-IKs alpha-subunit interaction. Heart Rhythm 6, 1792-1801. doi: 10.1016/j.hrthm. 2009.08.009

Boycott, H. E., Barbier, C. S., Eichel, C. A., Costa, K. D., Martins, R. P., Louault, F., et al. (2013). Shear stress triggers insertion of voltage-gated potassium channels from intracellular compartments in atrial myocytes. Proc. Natl. Acad. Sci. U.S.A. 110, E3955-E3964. doi: 10.1073/pnas.1309896110

Brundel, B. J., Van Gelder, I. C., Henning, R. H., Tuinenburg, A. E., Wietses, M., Grandjean, J. G., et al. (2001). Alterations in potassium channel gene expression in atria of patients with persistent and paroxysmal atrial fibrillation: differential regulation of protein and mRNA levels for $\mathrm{K}^{+}$channels. J. Am. Coll. Cardiol. 37, 926-932. doi: 10.1016/S0735-1097(00)01195-5

Choi, W. S., Khurana, A., Mathur, R., Viswanathan, V., Steele, D. F., and Fedida, D. (2005). Kv1.5 surface expression is modulated by retrograde trafficking of newly endocytosed channels by the dynein motor. Circ. Res. 97, 363-371. doi: 10.1161/01.RES.0000179535.06458.f8

Compton, S. J., Lux, R. L., Ramsey, M. R., Strelich, K. R., Sanguinetti, M. C., Green, L. S., et al. (1996). Genetically defined therapy of inherited long-QT syndrome: correction of abnormal repolarization by potassium. Circulation 94, 1018-1022. doi: 10.1161/01.CIR.94.5.1018

Costa, K. D., Takayama, Y., McCulloch, A. D., and Covell, J. W. (1999). Laminar fiber architecture and three-dimensional systolic mechanics in canine ventricular myocardium. Am. J. Physiol. 276(2 Pt 2), H595-H607. cells are necessary to improve our understanding of the mechanisms involved, and how they impact upon the pathology of arrhythmia.

\section{AUTHOR CONTRIBUTIONS}

All authors listed have made a substantial, direct and intellectual contribution to the work, and approved it for publication.

\section{FUNDING}

This work was supported by Fondation Leducq "Structural Alterations in the Myocardium and the Substrate for Cardiac Fibrillation" (EB), AFM-Téléthon (EB), and the European Union (EUTRAF-261057; EB and HB).

Ehrlich, J. R., Pourrier, M., Weerapura, M., Ethier, N., Marmabachi, A. M., Hébert, T. E., et al. (2004). KvLQT1 modulates the distribution and biophysical properties of HERG. A novel alpha-subunit interaction between delayed rectifier currents. J. Biol. Chem. 279, 1233-1241. doi: 10.1074/jbc.M309087200

Eichel, C. A., Beuriot, A., Chevalier, M. Y., Rougier, J.S., Louault, F., Dilanian, G., et al. (2016). Lateral membrane-specific MAGUK CASK downregulates NaV1.5 channel in cardiac myocytes. Circ. Res. 119, 544-556. doi: 10.1161/CIRCRESAHA.116.309254

El-Haou, S., Balse, E., Neyroud, N., Dilanian, G., Gavillet, B., Abriel, H., et al. (2009). Kv4 potassium channels form a tripartite complex with the anchoring protein SAP97 and CaMKII in cardiac myocytes. Circ. Res. 104, 758-769. doi: 10.1161/CIRCRESAHA.108.191007

Epshtein, Y., Chopra, A. P., Rosenhouse-Dantsker, A., Kowalsky, G. B., Logothetis, D. E., and Levitan, I. (2009). Identification of a C-terminus domain critical for the sensitivity of Kir2.1 to cholesterol. Proc. Natl. Acad. Sci. U.S.A. 106, 8055-8060. doi: 10.1073/pnas.0809847106

Fedida, D., Wible, B., Wang, Z., Fermini, B., Faust, F., Nattel, S., et al. (1993). Identity of a novel delayed rectifier current from human heart with a Cloned $\mathrm{K}^{+}$channel current. Circ. Res. 73, 210-216. doi: 10.1161/01.RES.73.1.210

Furutani, M., Trudeau, M. C., Hagiwara, N., Seki, A., Gong, Q., Zhou, Z., et al. (1999). Novel mechanism associated with an inherited cardiac arrhythmia: defective protein trafficking by the mutant HERG (G601S) potassium channel. Circulation 99, 2290-2294. doi: 10.1161/01.CIR.99.17.2290

Gillet, L., Rougier, J.-S., Shy, D., Sonntag, S., Mougenot, N., Essers, M., et al. (2015). Cardiac-specific ablation of synapse-associated protein SAP97 in mice decreases potassium currents but not sodium current. Heart Rhythm 12, 181-192. doi: 10.1016/j.hrthm.2014.09.057

Godreau, D., Vranckx, R., Maguy, A., Rücker-Martin, C., Goyenvalle, C., Abdelshafy, S., et al. (2002). Expression, regulation and role of the MAGUK protein SAP-97 in human atrial myocardium. Cardiovasc. Res. 56, 433-442. doi: 10.1016/S0008-6363(02)00602-8

Gouas, L., Bellocq, C., Berthet, M., Potet, F., Demolombe, S., Forhan, A., et al. (2004). New KCNQ1 mutations leading to haploinsufficiency in a general population; defective trafficking of a KvLQT1 mutant. Cardiovasc. Res. 63, 60-68. doi: 10.1016/j.cardiores.2004.02.011

Guo, J., Massaeli, H., Xu, J., Jia, Z., Wigle, J. T., Mesaeli, N., et al. (2009). Extracellular $\mathrm{K}^{+}$concentration controls cell surface density of IKr in Rabbit Hearts and of the HERG channel in human cell lines. J. Clin. Invest. 119, 2745-2757. doi: 10.1172/JCI39027

Guo, J., Wang, T., Yang, T., Xu, J., Li, W., Fridman, M. D., et al. (2011). Interaction between the cardiac rapidly (IKr) and slowly (IKs) activating delayed rectifier potassium channels revealed by low $\mathrm{K}^{+}$-induced $\mathrm{hERG}$ endocytic degradation. J. Biol. Chem. 286, 34664-34674. doi: 10.1074/jbc.M111.253351

Hong, T.T., Smyth, J. W., Chu, K. Y., Vogan, J. M., Fong, T. S., Jensen, B. C., et al. (2012). BIN1 is reduced and Cav1.2 trafficking is impaired in human failing cardiomyocytes. Heart Rhythm 9, 812-820. doi: 10.1016/j.hrthm.2011.11.055 
Kaufman, E. S., and Ficker, E. (2003). Is restoration of intracellular trafficking clinically feasible in the long QT syndrome?: the example of HERG mutations. J. Cardiovasc. Electrophysiol. 14, 320-322. doi: 10.1046/j.1540-8167.2003.02363.x

Kong, C. R., Bursac, N., and Tung, L. (2005). Mechanoelectrical excitation by fluid jets in monolayers of cultured cardiac myocytes. J. Appl. Physiol. 98, 2328-2336; discussion: 2320. doi: 10.1152/japplphysiol.01084.2004

Kruse, M., Schulze-Bahr, E., Corfield, V., Beckmann, A., Stallmeyer, B., Kurtbay, G., et al. (2009). Impaired endocytosis of the ion channel TRPM4 is associated with human progressive familial heart block type, I. J. Clin. Invest. 119, 2737-2744. doi: 10.1172/JCI38292

Kupershmidt, S., Yang, T., Chanthaphaychith, S., Wang, Z., Towbin, J. A., and Roden, D. M. (2002). Defective human ether-à-go-go-related gene trafficking linked to an endoplasmic reticulum retention signal in the C terminus. J. Biol. Chem. 277, 27442-27448. doi: 10.1074/jbc.M1 12375200

LeGrice, I. J., Takayama, Y., and Covell, J. W. (1995). Transverse shear along myocardial cleavage planes provides a mechanism for normal systolic wall thickening. Circ. Res. 77, 182-193. doi: 10.1161/01.RES.77.1.182

Leonoudakis, D., Mailliard, W., Wingerd, K., Clegg, D., and Vandenberg, C. (2001). Inward rectifier potassium channel Kir2.2 is associated with synapse-associated protein SAP97. J. Cell Sci. 114(Pt 5), 987-998.

Lin, X., Liu, N., Lu, J., Zhang, J., Anumonwo, J. M., Isom, L. L., et al. (2011). Subcellular heterogeneity of sodium current properties in adult cardiac ventricular myocytes. Heart Rhythm 8, 1923-1930. doi: 10.1016/j.hrthm.2011.07.016

Lorenzen-Schmidt, I., Schmid-Schönbein, G. W., Giles, W. R., McCulloch, A. D., Chien, S., and Omens, J. H. (2006). Chronotropic response of cultured neonatal Rat ventricular myocytes to short-term fluid shear. Cell Biochem. Biophys. 46, 113-122. doi: 10.1385/CBB:46:2:113

Lundbaek, J. A., Birn, P., Girshman, J., Hansen, A. J., and Andersen, O. S. (1996). Membrane stiffness and channel function. Biochemistry 35, 3825-3830. doi: $10.1021 / \mathrm{bi} 952250 \mathrm{~b}$

Matamoros, M., Pérez-Hernández, M., Guerrero-Serna, G., Amorós, I., Barana, A., Nú-ez, M., et al. (2016). Nav1.5 N-terminal domain binding to $\alpha 1$-syntrophin increases membrane density of human Kir2.1, Kir2.2 and Nav1.5 channels. Cardiovasc. Res. 110, 279-290. doi: 10.1093/cvr/cvw009

McEwen, D. P., Schumacher, S. M., Li, Q., Benson, M. D., I-iguez-Lluhí, J. A., Van Genderen, K. M., et al. (2007). Rab-GTPase-dependent endocytic recycling of Kv1.5 in atrial myocytes. J. Biol. Chem. 282, 29612-29620. doi: 10.1074/jbc.M704402200

Mehta, A., Sequiera, G. L., Ramachandra, C. A., Sudibyo, Y., Chung, Y., Sheng, J., et al. (2014). Re-trafficking of hERG reverses long QT syndrome 2 phenotype in human iPS-derived cardiomyocytes. Cardiovasc. Res. 102, 497-506. doi: $10.1093 / \mathrm{cvr} / \mathrm{cvu} 060$

Milstein, M. L., Musa, H., Balbuena, D. P., Anumonwo, J. M., Auerbach, D. S., Furspan, P. B., et al. (2012). Dynamic reciprocity of sodium and potassium channel expression in a macromolecular complex controls cardiac excitability and arrhythmia. Proc. Natl. Acad. Sci. U.S.A. 109, E2134-E2143. doi: 10.1073/pnas.1109370109

Morad, M., Javaheri, A., Risius, T., and Belmonte, S. (2005). Multimodality of Ca2+ signaling in Rat atrial myocytes. Ann. N. Y. Acad. Sci. 1047, 112-121. doi: 10.1196/annals. 1341.010

Oliver, D., Lien, C.-C., Soom, M., Baukrowitz, T., Jonas, P., and Fakler, B. (2004). Functional conversion between A-type and delayed rectifier $\mathrm{K}^{+}$channels by membrane lipids. Science 304, 265-270. doi: 10.1126/science.1094113

Organ-Darling, L. E., Vernon, A. N., Giovanniello, J. R., Lu, Y., Moshal, K., Roder, K., et al. (2013). Interactions between hERG and KCNQ1 $\alpha$-subunits are mediated by their $\mathrm{COOH}$ termini and modulated by cAMP. Am. J. Physiol. Heart Circ. Physiol. 304, H589-H599. doi: 10.1152/ajpheart.00385.2012

Petitprez, S., Zmoos, A.-F., Ogrodnik, J., Balse, E., Raad, N., El-Haou, S., et al. (2011). SAP97 and dystrophin macromolecular complexes determine two pools of cardiac sodium channels Nav1.5 in cardiomyocytes. Circ. Res. 108, 294-304. doi: 10.1161/CIRCRESAHA.110.228312

Rajamani, S., Anderson, C. L., Anson, B. D., and January, C. T. (2002). Pharmacological rescue of human $\mathrm{K}^{+}$channel long-QT2 mutations: human ether-a-go-go-related gene rescue without block. Circulation 105, 2830-2835. doi: 10.1161/01.CIR.0000019513.50928.74

Ren, X. Q., Liu, G. X., Organ-Darling, L. E., Zheng, R., Roder, K., Jindal, H. K., et al. (2010). Pore mutants of HERG and KvLQT1 downregulate the reciprocal currents in stable cell lines. Am. J. Physiol. Heart Circ. Physiol. 299, H1525-H1534. doi: 10.1152/ajpheart.00479.2009

Rucker-Martin, C., Milliez, P., Tan, S., Decrouy, X., Recouvreur, M., Vranckx, R., et al. (2006). Chronic hemodynamic overload of the Atria is an important factor for gap junction remodeling in human and Rat hearts. Cardiovasc. Res. 72, 69-79. doi: 10.1016/j.cardiores.2006.06.016

Sanguinetti, M. C., Curran, M. E., Zou, A., Shen, J., Spector, P. S., Atkinson, D. L., et al. (1996). Coassembly of K(V)LQT1 and minK (IsK) proteins to form cardiac I(Ks) potassium channel. Nature 384, 80-83. doi: 10.1038/384080a0

Sanguinetti, M. C., Jiang, C., Curran, M. E., and Keating, M. T. (1995). A mechanistic link between an inherited and an acquired cardiac arrthytmia: HERG encodes the IKr potassium channel. Cell 81, 299-307. doi: 10.1016/0092-8674(95)90340-2

Sanguinetti, M. C., and Tristani-Firouzi, M. (2006). hERG potassium channels and cardiac arrhythmia. Nature 440, 463-469. doi: 10.1038/nature04710

Schotten, U., Verheule, S., Kirchhof, P., and Goette, A. (2011). Pathophysiological mechanisms of Atrial fibrillation: a translational appraisal. Physiol. Rev. 91, 265-325. doi: 10.1152/physrev.00031.2009

Schumacher, S. M., McEwen, D. P., Zhang, L., Arendt, K. L., Van Genderen, K. M., and Martens, J. R. (2009). Antiarrhythmic drug-induced internalization of the atrial-specific $\mathrm{k}^{+}$channel kv1.5. Circ. Res. 104, 1390-1398. doi: 10.1161/CIRCRESAHA.108.192773

Shaw, R. M., Fay, A. J., Puthenveedu, M. A., von Zastrow, M., Jan, Y. N., and Jan, L. Y. (2007). Microtubule plus-end-tracking proteins target gap junctions directly from the cell interior to adherens junctions. Cell 128, 547-560. doi: 10.1016/j.cell.2006.12.037

Shy, D., Gillet, L., and Abriel, H. (2014). Targeting the sodium channel NaV1.5 to specific membrane compartments of cardiac cells: not a simple task! Circ. Res. 115, 901-903. doi: 10.1161/CIRCRESAHA.114.305305

Spach, M. S. (1999). Anisotropy of cardiac tissue: a major determinant of conduction? J. Cardiovasc. Electrophysiol. 10, 887-90. doi: 10.1111/j.1540-8167.1999.tb00271.x

Steele, D. F., Eldstrom, J., and Fedida, D. (2007). Mechanisms of cardiac potassium channel trafficking. J. Physiol. 582(Pt 1), 17-26. doi: 10.1113/jphysiol.2007.130245

Trudeau, M. C., Warmke, J. W., Ganetzky, B., and Robertson, G. A. (1995). HERG, a human inward rectifier in the voltage-gated potassium channel family. Science 269, 92-95. doi: 10.1126/science.7604285

Valdivia, C. R., Tester, D. J., Rok, B. A., Porter, C. B., Munger, T. M., Jahangir, A., et al. (2004). A trafficking defective, brugada syndromecausing SCN5A mutation rescued by drugs. Cardiovasc. Res. 62, 53-62. doi: $10.1016 /$ j.cardiores.2004.01.022

Van Wagoner, D. R., Pond, A. L., McCarthy, P. M., Trimmer, J. S., and Nerbonne, J. M. (1997). Outward $\mathrm{K}^{+}$current densities and Kv1.5 expression are reduced in chronic human atrial fibrillation. Circ. Res. 80, 772-781. doi: 10.1161/01.RES.80.6.772

Verkerk, A. O., van Ginneken, A. C., van Veen, T. A., and Tan, H. L. (2007). Effects of heart failure on brain-type $\mathrm{Na}+$ channels in Rabbit ventricular myocytes. Europace 9, 571-577. doi: 10.1093/europace/eum121

Wang, Z., Fermini, B., and Nattel, S. (1993). Sustained depolarization-induced outward current in human atrial myocytes. evidence for a novel delayed rectifier $\mathrm{K}^{+}$current similar to Kv1.5 cloned channel currents. Circ. Res. 73, 1061-1076. doi: 10.1161/01.RES.73.6.1061

Wible, B. A., Hawryluk, P., Ficker, E., Kuryshev, Y. A., Kirsch, G., and Brown, A. M. (2005). HERG-Lite: a novel comprehensive high-throughput screen for drug-induced hERG risk. J. Pharmacol. Toxicol. Methods 52, 136-145. doi: $10.1016 /$ j.vascn.2005.03.008

Conflict of Interest Statement: The authors declare that the research was conducted in the absence of any commercial or financial relationships that could be construed as a potential conflict of interest.

Copyright $\odot 2017$ Balse and Boycott. This is an open-access article distributed under the terms of the Creative Commons Attribution License (CC BY). The use, distribution or reproduction in other forums is permitted, provided the original author(s) or licensor are credited and that the original publication in this journal is cited, in accordance with accepted academic practice. No use, distribution or reproduction is permitted which does not comply with these terms. 